\title{
Komposisi Bahan Volatil Ekstraks Kulit batang Antiaris toxicaria Lesch yang Tumbuh di Pulau Kalimantan
}

\author{
Tjatjuk Subiono ${ }^{1}$ dan Sadarudin ${ }^{2}$ \\ 1,2 Fakultas Pertanian Universitas Mulawarman, Gunung Kelua Jalan Pasir \\ Balengkong, Samarinda Kalimantan Timur \\ 1Email : tjatjuksubiono@ymail.com
}

\begin{abstract}
Antiaris spp. that grows on the island of Borneo has been known as a plant on the bark produces sap and has been used as chopstick poison and traditional medicine. But until now there has been no research report on the content of volatile components in the bark of these plants. This research was conducted at the Organic Chemistry Laboratory (Volatile material extraction), GC-MS/MS analysis in the laboratory of the UB Center for Biological Sciences, in August-October 2017. The purpose of the study was to provide information about the chemical composition of essential oils in the Antiaris spp burk produced from the method distillation. Distillate was extracted with 2 different polarity solvents, $n$-hexane and ethyl acetate. The chemical composition of the extract was then analyzed by GC-MS/MS. The results of GC-MS/MS analysis on $n$-hexane solvents showed the presence of volatile compounds such as isoforon (35.795\%), citronellal (0.52\%), B-patchoulene (0.186\%), geranyl acetate (0.377\%), Z-3 - hexadecene (0.52\%), $\beta$-patchoulene (0.186\%), geranyl acetate (0.377\%), Z-3 - hexadecene (0.52\%). 0.543\%), geranyl butyrate (0.323\%), palmitic acid $(0.677 \%)$, terpenol $(0.352 \%)$, terpeniol hydrate $(0.246 \%)$ and citronellyl acetate $(0.233 \%)$. Whereas in the ethyl acetate solvent containing $\beta$-patchoulene (1,799\%), $\alpha$-hexyl cinnamaldehyde (0.949\%), alpha-octadecene (6.135\%), myristic alcohol (3.554\%) and hexadecanoic acid $(5.724 \%)$. The $n$-hexane solvent gives a more complex volatile material than ethyl acetate.
\end{abstract}

Keywords : Antiaris toxicaria Lesch, Essential oils, Gas chromatography, Kalimantan's plants, Volatile components.

\begin{abstract}
ABSTRAK
Antiaris spp yang tumbuh di pulau Kalimantan telah dikenal sebagai tanaman pada kulit batangnya menghasilkan getah dan telah digunakan sebagai racun sumpit dan obat tradisional. Namun hingga saat ini belum ada laporan penelitian tentang kandungan komponen volatil di kulit batang tanaman tersebut. Penelitian ini dilaksanakan di Laboratorium Kimia Organik (Ekstraksi bahan volatil), analisis GC-MS di laboratorium Pusat IImu Hayati Universitas Brawijaya, pada bulan Agustus-Oktober 2017. Tujuan penelitian untuk memberikan informasi tentang komposisi kimia minyak atsiri dalam kulit Antiaris spp yang dihasilkan dari metode destilasi. Distilat diekstraksi dengan 2 pelarut polaritas yang berbeda yaitu $n$-heksana dan etil asetat. Komposisi kimiawi ekstrak tersebut kemudian dianalisis dengan GC-MS. Hasil analisis GC-MS pada pelarut $n$ heksana menunjukkan adanya senyawa volatil seperti isoforon $(35,795 \%)$, sitronelal $(0,52 \%), \beta$-patchoulene $(0,186 \%)$, geranyl acetate $(0,377 \%)$, Z-3 - hexadecene $(0,543 \%)$, geranyl butyrate $(0,323 \%)$, asam palmitat $(0,677 \%)$, terpenol $(0,352 \%)$, terpeniol hidrat $(0,246 \%)$ dan citronellyl acetate $(0,233 \%)$. Sedangkan dalam pelarut etil asetat mengandung $\beta$-patchoulene $(1,799 \%)$, $\alpha$-hexyl cinnamaldehyde $(0,949 \%)$, alpha-octadecene $(6,135 \%)$, alkohol miristat $(3,554 \%)$ dan asam heksadekanoat $(5,724 \%)$. Pelarut $n$-heksan memberikan hasil bahan volatil yang lebih kompleks dibandingkan etil asetat.
\end{abstract}

Kata kunci: Antiaris toxicaria Lesch, Gas kromatografi, Komponen volatile, Minyak atsiri, Tumbuhan Kalimantan.

\section{Pendahuluan}

Antiaris toxicaria L merupakan tanaman berkayu (Famili Moraceae), yang dapat mencapai ketinggia 30-40 m, memiliki sekitar 40 genera. Sebaran tanaman ini umumnya tumbuh baik di daerah tropis dan subtropis. Famili Spesies ini umumnya mengeluarkan 
lateks (getah) bewarna putih susu dan daun simetris (Gan et. al., 2008 ; Que et al. 2009; Carter et al., 1997), bunga jantan dan betina kurang berkelopak. Buah pada tanaman spesies ini sebagian besar berpolong (Fujimoto, et al., 1992; Dai et. al., 2010.). A. toxicaria ditemukan dihutan kering dan basah serta di padang rumput berhutan (preiri) tropis. Hutan sekunder merupakan habitat yang umum dapat ditemui tanaman ini karena kemampuan tumbuh yang sangat tinggi dalam persaingan dengan tanaman di lingkungannya (Gambar 1). Memiliki banyak nama daerah di pulau Kalimantan dikenal sebagai tanaman ipoh (tanaman racun) dan nama lain seperti Akede, Ako, Andoum, jelmu dan beberapa nama daerah.

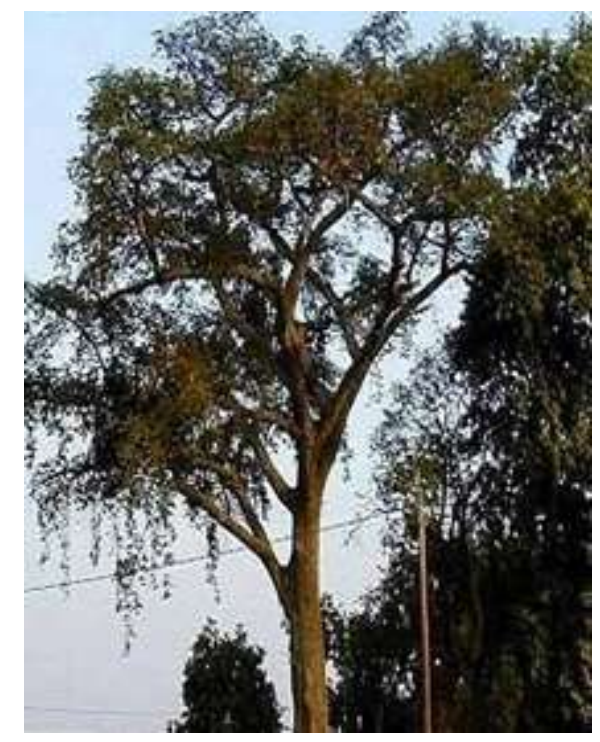

Gambar 1. Pohon Antiaris toxicaria diagroekosistem

Kulit yang bergetah/lateks digunakan obat tradisional di pulau Kalimantan oleh suku Dayak dimanfaatkan sebagai racun panah dan racun sumpit. Hasil lateks dari kulit pohon/tanaman $A$. toxicaria yang dilukai mencapai 1 - 2 liter per hari tergantung ukuran pohonnya. Di Afrika lateks yang berasal dari tanaman $A$. africana dimanfaatkan untuk pengobatan penyakit ayan atau gangguan syaraf lainnya (Odugbemi, 2008). Suku yang lain di Afrika memanfaatkan getah lateks sebagai racun panah alat untuk mempertahankan diri. Biji, daun dan kulit kayu digunakan sebagai obat penurun panas dan biji dimanfaatkan sebagai antidisentri (Fujimoto et. al., 1983). Kulit batang digunakan sebagai obat penenang saat melahirkan, dan untuk mengobati hepatitis, pewarnaan hiasan pada kain-kain tradisional. Bagian jaringan kulit kayu dimanfaatkan untuk membuat pakaian kasar dan kertas. Ekstrak etanol kulit batang memiliki efek kardiotonik pada pengujian in vitro hewan uji marmot atrium (Shi et al., 2010 ; Jiang et. al., 2009 ; Mei, et al, 2011). Daun dan akar digunakan untuk mengobati penyakit jiwa oleh dukun-dukun kampung. Kayu yang dihasilkan tanaman ini merupakan kayu golongan $\mathrm{C}$, baik untuk perkakas rumah dan peruntukan bangunan (Nordal, 1963). 
A. toxicaria tanaman yang beracun sudah mulai langka akibat pembalakan dan dianggap sebagai tanaman berbahaya karena beracun bagi masyarakat tradisional. Beberapa ekstrak non volatile dari kulit batang dari spesies $A$. Africana diantaranya asam

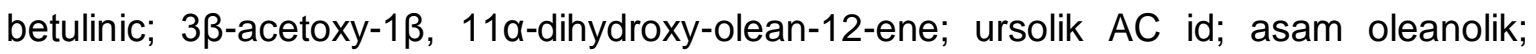
strophanthidol; periplogenin; convallatoxin; asam strophanthidinic; methyl trophanthinate dan 3,3'-dimethoxy-asam 4'-O- $\beta$-d-xylopyronosylellagic. Sumber obat potensial untuk pengobatan kanker, juga anti oksidannya yang menarik untuk dikembangkan (Kuete et al., 2009; Okogun et al., 1976). Empat senyawa diisolasi dari kulit batang A. africana. Mereka adalah lichenxanthone, $\beta$-sitosterol, betulinic asam dan $\gamma$-lakton bernama antialactone (Bertina et al., 2008) dan beberapa komponen etno botanik di Nigeria. Bahan aktif dari getah toxicarioside memiliki daya tosik pada tikus, di masa yang akan datang hasil getah tanaman ini dapat dimanfaatkan sebagai bahan aktif rodentisida (Subiono, et al., 2017). Penelitian ini mengetahui komponen minyak atsiri (volatile oil) dari kulit batang Antiaris toxicaria dengan pelarut berbeda polaritasnya $n$ - heksan dan etil asatat.

\section{Metode Penelitian}

\section{Bahan Tumbuhan}

Bahan kulit kayu dari daerah Bentian Besar Kutai Barat, merupakan tanaman asal menurut penduduk setempat. Bahan berupa (sampel tanaman) daun, kulit batang dan foto hasil investigasi dibawa ke Samarinda untuk diidentifikasi oleh ahli tasonomi kebun raya samarinda untuk dibandingkan dengan herbarium dan tanaman in situ yang tumbuh di Kebun raya samarinda.

\section{Pemisahan Minyak Atsiri}

Kulit batang ditimbang $1000 \mathrm{~g}, 500 \mathrm{~g}$ dipotong $10 \mathrm{~cm}^{2}$ selanjutnya direndam 24 jam dengan pelarut $\mathrm{n}$-heksan dan pekerjaan yang sama $500 \mathrm{~g}$ direndam dengan etil asetat, masing-masing hasil tersebut didestialasi dengan piranti destilasi Clavenger selama 5 jam dengan mempertahankan suhu larutan $\left(<90^{\circ} \mathrm{C}\right)$ dengan menjaga kestabilan sumber pemanas. Hasil destilasi berupa volatil oil masing-masing 1,36 $\mathrm{g}$ dengan pelarut etil. asetat dan pelarut $\mathrm{n}$-heksan $2.64 \mathrm{~g}$ atau pelarut etil asetat $0.272 \%$ dan $\mathrm{n}$-heksan $0.528 \%$ Konsentrasi bahan hasil destilasi relatif kecil diperlukan teknik ekstraksi yang tepat serta instrumen yang mendukung untuk menganalisa suatu senyawa dalam komposisi yang salah satu instrumen yang dapat mendeteksi suatu senyawa hingga $<1 \mathrm{ng} / \mathrm{g}$ adalah Kromatografi Gas-Spektrometri Massa (GC-MS).

GC-MS/MS (Gas Kromatrografi Masa Spektrometri). Hasil volatil oil dipadatkan dengan gas nitrogen $\left(\mathrm{N}_{2}\right)$ selanjutnya dianalisis di Laboratorium Sentral IImu Hayati Universitas Brawijaya. Teknik khusus yang dipilih sebelum sampel diinjeksikan ke dalam 
sistem GC-MS, salah satunya adalah teknik derivatisasi. Teknik ini digunakan hanya untuk kompilasi yang ingin dipecahkan dan sulit untuk digunakan pada suhu tinggi.

\section{Identifikasi Komponen}

Indeks retensi hasil analisis dan dibandingkan dengan homolog-nya dengan sistem masa komersilnya. Data Chemstation System Willey GC-MS/MS sebagai langkah awal pembandingan dan analis (Massada, 1976) selanjutnya Kepustakaan Baser Konstituen volatil dan senyawa asli komponen volatil yang dikenal (Joulain \& Koenig, 1998).

\section{Hasil dan Pembahasan}

$A$, toxicaria spesies tanaman yang keberadaannya sudah sangat jarang dan memerlukan investigasi dan pendekatan mendalam untuk mendapatkan simplisia berupa getah, kulit batang dan daun tanaman. Kulit batang tanaman dikemas dalam kotak plastik dan setiap helai kulit dibungkus dengan tinfoil. Minyak atsiri yang diperoleh dari etil asetat destilasi $0.272 \%$ dan pelarut dan $n$-heksan destilasi $0.528 \%$, perbedaan persen tersebut karena perbedaan nilai polaritas pelarut.

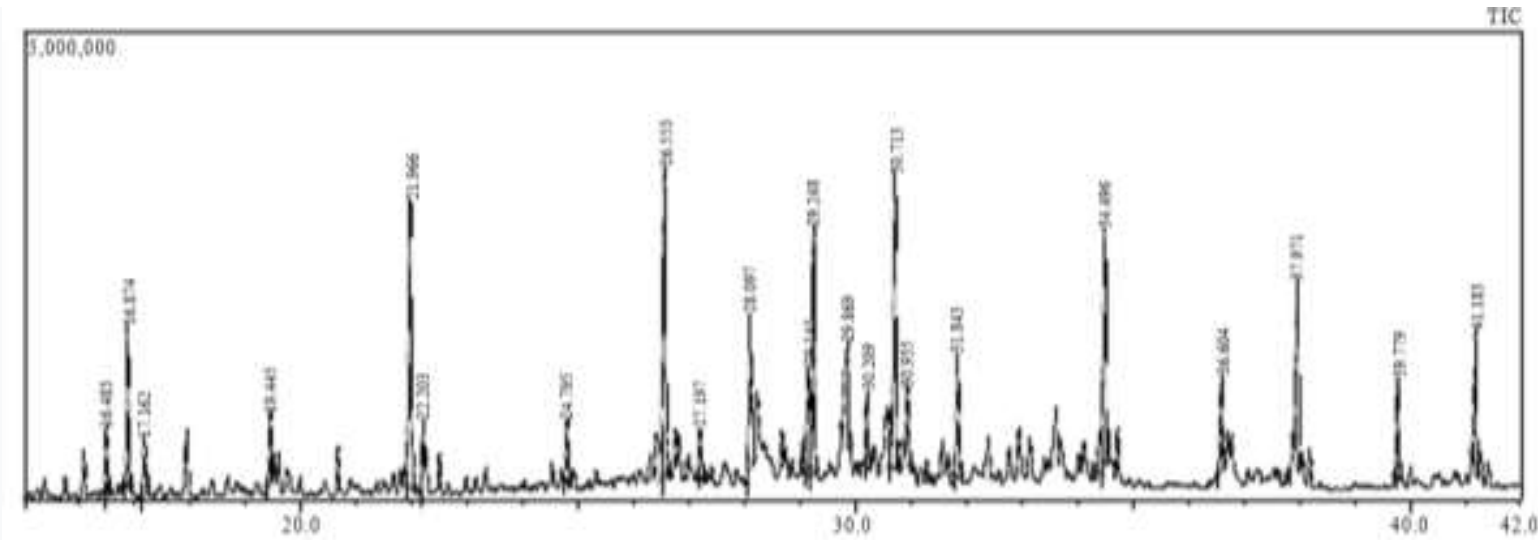

Gambar 2. Chromatogram GC-MS/MS kulit batang A. toxicaria dengan pelarut Etil Asetat.

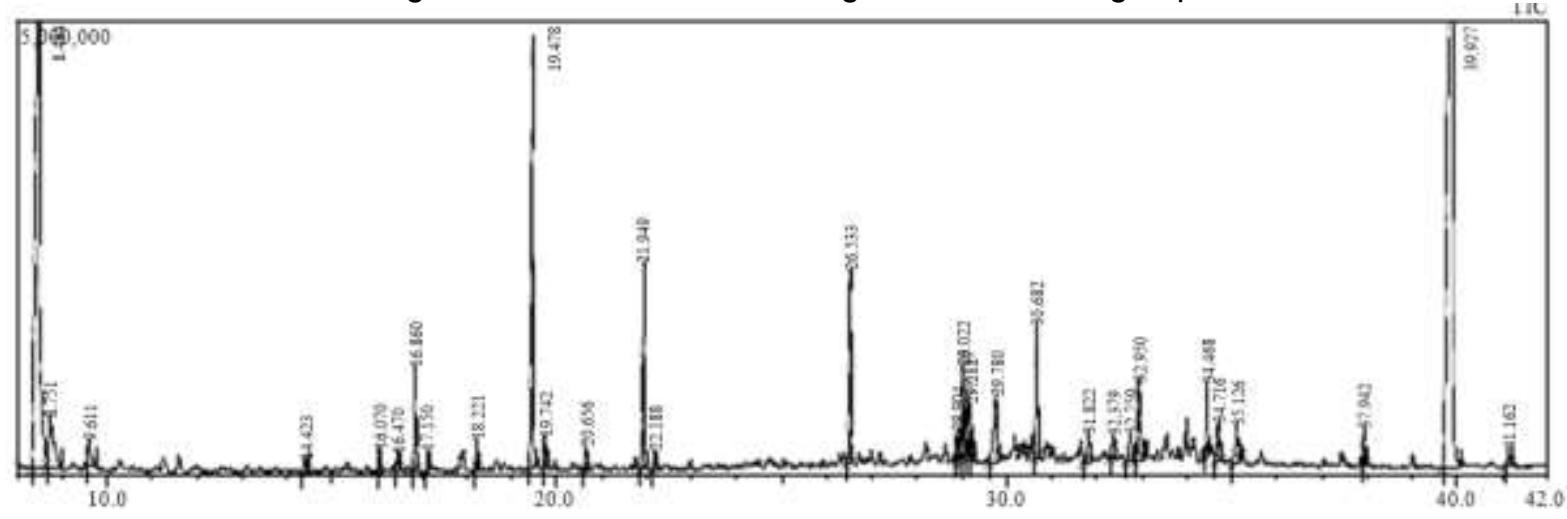

Gambar 3. Chromatogram GC-MS/MS kulit batang $A$. toxicaria dengan pelarut $\mathrm{n}$-heksan

Hasil analisis GC-MS/MS terdapat 23 volatil oil dari et.asetat destilasi kulit batang

A. toxicaria merupakan $0.272 \%$ dan dari $n$-heksan destilasi terdapat 31 volatil oil penyusun kulit batang $A$. toxicaria merupakan $0.528 \%$ dari $500 \mathrm{~g}$ kulit batang yang diekstrak. Persen keberadaan bervariasi dari 1-13 dan $0.2-36 \%$ dari total volatil oil yang terdeteksi 
ISSN 2354-7251 (print)

sedangkan pada pelarut etil asetat terdapat 23 volatil oil beta-patchoulene $(1,799 \%)$, $\alpha$ hexyl cinnamaldehyde (0,949\%), alpha-octadecene (6,135\%), alkohol miristat $(3,554 \%)$ dan asam heksadekanoat (5,724\%). Bahan-bahan volatil tersebut memiliki khasiat yang sama dengan kapur barus. (Chromatogram Gambar 2 dan 3).

Tabel 1. Hasil kuantitatif GC-MS/MS kulit batang A. toxicaria dengan pelarut Etil Asetat

\begin{tabular}{|c|c|c|c|c|c|}
\hline Nama volatile oil & Waktu retensi & $\mathrm{mz}$ & Area & ketinggian & \\
\hline \multicolumn{6}{|l|}{ konsentrası } \\
\hline 1 beta. Patchoulene & 16.483 & 101.00 & 300996 & 98893 & $1.7994 \mathrm{~h}$ \\
\hline 2 3-Hexadecene, $(Z)$ - (CAS) & 16.1874 & 43.00 & 484018 & 179488 & $2.830 \%$ \\
\hline 3 Tetradecanie (CAS) n-Tetradecane & 17,162 & 57,00 & 418001 & 147391 & $2.453 \%$ \\
\hline 4 Phenol 2,4-biv(1,1-dinetinylethyl) (CAS) 2,42 & 19.443 & 191.00 & 608435 & 225660 & $3,569 \%$ \\
\hline 5 1-Hexadecene (CAS) Cetene & 21.967 & 43.00 & 911960 & 299831 & $5,350 \%$ \\
\hline 6 Pentadecane (CAS) a-Pentadecane & 22.203 & 57.00 & 543808 & 191166 & $3.101 \% 6$ \\
\hline 7 Otanal, 2-(phenyluethylene)-(CAS) Hexy4 eit & 24.796 & 216.00 & 161810 & $\$ 8261$ & $0.940 \% 6$ \\
\hline \& 1-Octadecene (CAS) alpha. Octadecene & 26.553. & 57.00 & 1045828 & 332908 & $6.135 \%$ \\
\hline 9 Hexarnetiryl-pyranoindane & 27,103 & 243,00 & 326006 & 97020 & $1.013 \%$ \\
\hline 10 1-Tetrudecinol (CAS)-Alfol 14 & 28.006 & 55,00 & 605750 & 158082 & $3.554 \%$ \\
\hline il 1,2-Benzenedicatboxytio acid, diburyl ester (C) & 29.144 & 149.00 & 2322463 & 706888 & $13.625 \%$ \\
\hline 12 Elhabe, 1.1-oxybiul2-ethory- (CAS) Biv(2-ettu & $20.24 \%$ & 81.00 & 1229027 & 398498 & $7,210 \%$ \\
\hline 13 Hesadecanoie acid (CAS) Palsizic acid & 20.800 & 73,00 & 975752 & 146301 & $5.724 \%$ \\
\hline 14 Ethane, 1,1-oxytris/2-ethoxy-(CAS) Bis/2-eth & 30.208 & 81.00 & 411950 & 131530 & $2,417 \%$ \\
\hline is Cyclotetracosane (CAS) & 30.713 & 57,00 & 1013.302 & 332912 & $5.944 \%$ \\
\hline 16 CYCLOHEXANOL. 2-(2-HYDROXY-2-PROH & 30.90 & 81,00 & 366280 & 130341 & $2.140 \%$ \\
\hline 17 CYCLOHINANOL, 2-(2-HYDROXY2-PRO & 31.840 & 81.00 & 686978 & 204073 & $4.030 \%$ \\
\hline 18 Cyclotetracosane (CAS) & 34.496 & $\$ 7.00$ & 880343 & 200820 & $5.217 \%$ \\
\hline 19 90.Oudecenanide, (C)-(CAS) OL FOAMADE & 36.604 & 99.00 & 905693 & 256234 & $5.313 \%$ \\
\hline 20 Cyclotetrasosane (CAS) & 37.971 & 57.00 & 882822 & 247936 & $5.170 \%$ \\
\hline 21 1.2-Benzenedicauboxylic acid, disooctyl ester i & 39.770 & 149,00 & 840140 & 302548 & $4.920 \%$ \\
\hline 22 1-Pentacontanol (CAS') N-PENTACONTANOT & 41.185 & $\$ 7.00$ & 661761 & 192775 & $3.882 \%$ \\
\hline 23 1-Hentetracontanol (CAS) N.HINNIETRACOA & 44.165 & 57.00 & 448312 & 139224 & $2.630 \%$ \\
\hline
\end{tabular}

$\mathrm{N}$-heksan dan etil asetat merupakan pelarut organik non polar dan semi polar masing-masing pelarut berbeda berbeda titik didihnya, n-heksan $\left(69^{\circ} \mathrm{C}\right)$ dan etil asetat $\left(79^{\circ} \mathrm{C}\right)$, konstanta dielektrik $(2,3$ dan 6,0$)$ dan massa jenis $(0,879 \mathrm{~g} / \mathrm{ml}$ dan $0,894 \mathrm{~g} / \mathrm{ml})$. Perbedaan titik didih, konstanta dielektrik sifat inert $n$-heksan diduga pengikatannya terhadap volatil oil lebih kuat sehingga diperoleh jenis volatil yang lebih banyak dibandingkan pelarut etil asetat. Titik didih pelarut $\mathrm{n}$-heksan $69^{\circ} \mathrm{C}$ merupakan suhu ideal bahan-bahan volatil yang terikat pada sel untuk menguap dan terlarut dan terjerab pada pelarut. Titik didih etil asetat $79^{\circ} \mathrm{C}$ yang menjadi sifat dari pelarut tersebut, bahan-bahan volatil sudah banyak yang menguap dan lebih sedikit bahan volatil dalam sel kulit batang yang terjerab oleh pelarut etil asetat.

Tabel 2. Hasil kuantitatif GC-MS/MS kulit batang A. toxicaria dengan pelarut n-heksan

\begin{tabular}{|c|c|c|c|c|c|c|}
\hline \multicolumn{2}{|c|}{ Nama volatile oil } & Waktu retensi & $\mathrm{mz}$ & Area & ketinggian & \\
\hline \multicolumn{7}{|c|}{ konsentrasi } \\
\hline I & 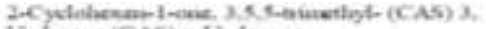 & $=.+46$ & 0.00 & 17800014 & 2023402 & $35 \times 20256$ \\
\hline 2 & 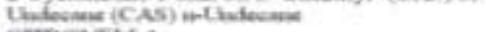 & 2748 & $\$ 7.00$ & stesos & 13159 & $1710 \%$ \\
\hline 3 & crmocentila & 9012 & 4t.00 & 265004 & $9+580$ & 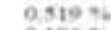 \\
\hline & 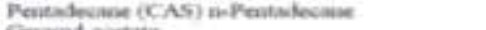 & 14.43 & 57,00 & 92779 & $27 m 0 s$ & 0.180:- \\
\hline & Covavol acptate & 10070 & 00.00 & 1*7og: & ostat 1 & 0,9776 \\
\hline & 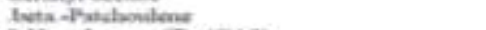 & 16.471 & $161 \infty$ & 7346 & $2+661$ & $0.140 *$ \\
\hline & 3-Hecunderase, $(2)$-(CAS) & 16500 & 4.00 & 270004 & 105415 & $045 \%$ \\
\hline $\mathrm{s}$ & 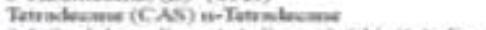 & 17.160 & $57, \infty 0$ & 163261 & soust & 6327. \\
\hline 9 & 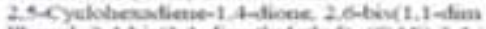 & in. 230 & 220000 & 113273 & 39586 & 02275 \\
\hline 10 & 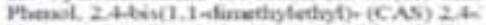 & 19.477 & 192.00 & 5375000 & 104000\% & 10.782 .68 \\
\hline ii & 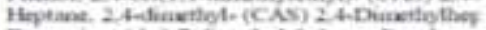 & 19.74 & 49.00 & 323004 & 130705 & $0.040 \div$ \\
\hline 12 & 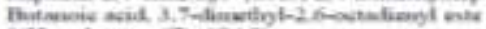 & 20.656 & 00.00 & 160097 & 66900 & a. 723.9 \\
\hline 23 & 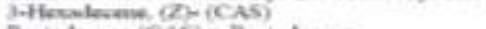 & 21.040 & 5900 & 600246 & 234726 & 1.2129. \\
\hline 14 & 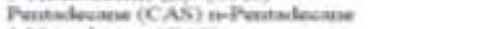 & 22.180 & 5700 & 143750 & solaz & o.jas 4 \\
\hline is & 1. Honidecone (CAS) & 20.533 & 57,00 & arase & 228400 & $1.240 \%$ \\
\hline 10 & 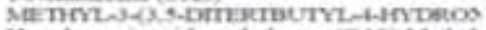 & 28.900 & 277,00 & 120060 & te939 & 0.2954 \\
\hline 17 & 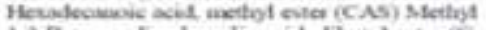 & 20.022 & 74.00 & 710120 & 273678 & $1.424=6.60$ \\
\hline is & 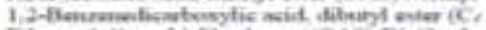 & 20.110 & $1+0.00$ & $11+4513$ & $+007+40$ & $2.903 *$ \\
\hline 19 & 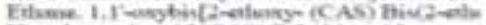 & 20213 & 81.00 & 200030 & 101360 & $6.452 * 1$ \\
\hline 30 & 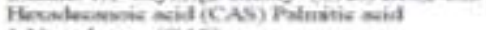 & 20.780 & 20.00 & 397971 & $\infty 604$ & $0.67 \%$ \\
\hline 21 & 1. Nonialecente (CAS) & 30.032 & 57.00 & 43,3901 & 191973 & axen 5 \\
\hline 22 & 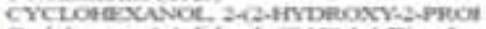 & 31.819 & st.00 & $173 \times 34$ & 46015 & $0.392 * 8$ \\
\hline 23 & 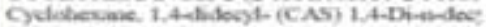 & 32.979 & 223.00 & 93750 & 32000 & $0.183-7$ \\
\hline 24 & Conomelibt acetate & 32.757 & 60.00 & 116130 & 20505 & 0.23346 \\
\hline 25 & 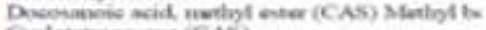 & 93999 & $7+00$ & 21670 s & 31702 & 0.4354 \\
\hline 26 & Cyclotentioname (CAS) & 3.46 & $\$ 700$ & 26.6572 & 101525 & $6.571+6$ \\
\hline 27 & 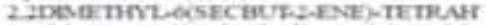 & 34.718 & 43.00 & 197633 & yesese & $0.316 \%$ \\
\hline 28 & 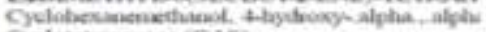 & 35.125 & 43.00 & 122805 & 40997 & $0.240 \%$ \\
\hline Io & Cyclotetraconane (CAS) & 37942 & 57,00 & 160248 & 52473 & $0333 \%$ \\
\hline & 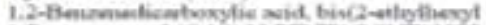 & 39.922 & 149.00 & $182981 \mathrm{kz}$ & 2435100 & $36.000 \%$ \\
\hline 31 & 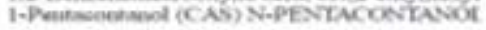 & 41. 102 & 57,00 & $\$ 4676$ & 24560 & $0.170 \div$ \\
\hline
\end{tabular}


Hasil ekstrak etil asetat destilasi (Tabel 1), terjerab 1,2-Benzenedicarboxylic acid, dibutyl ester (CAS) Butyl phthalate berkadar $13.625 \%$, Ethane, 1,1'-oxybis[2-ethoxy(CAS) Bis(2-ethoxyethyl) dengan konsentrasi $7.210 \%$, 1-Octadecene (CAS) a.Octadecene sejumlah $6.135 \%$ merupakan volatil oil yang mendominasi kulit batang $A$. toxicaria. Bahan volatil oil ini homolog dengan bahan hasil ekstrak pada getah tanaman barus (Joulain \& Koenig, 1998). Produk getah tanaman barus adalah kapur barus yang dimanfaatkan sebagai anti jamur, serangga bahan sandang yang disimpan lemari atau gudang. Bahan volatil oil dengan konsentrasi yang lebih kecil yaitu $>5 \%$ merupakan volatil oil susquiterpenne yang menyebarkan aroma khas penciri dari tanaman diantaranya 1 Hexadecene (CAS) Cetene $5.350 \%$, Hexadecanoic acid (CAS) Palmitic acid $5.724 \%$, Cyclotetracosane (CAS) $5.944 \%$, Cyclotetracosane (CAS) $5.217 \%$, 9-Octadecenamide, (Z)-(CAS) oleoamide $5.313 \%$, Cyclotetracosane (CAS) $5.179 \%$.

Hasil ekstrak n-heksan destilasi ini mengungkap kandungan bahan-bahan volatil yang biasa dimanfaatkan, senyawa volatil seperti isoforon (35,795\%), sitronelal (0,52\%), $\alpha$ patchoulene $(0,186 \%)$, geranyl asetat $(0,377 \%)$, Z-3 - hexadecene $(0,543 \%)$, geranyl butyrate $(0,323 \%)$, asam palmitat $(0,677 \%)$, terpenol $(0,352 \%)$, terpeniol hidrat $(0,246 \%)$ dan citronellyl acetate $(0,233 \%)$ (Tabel 2$)$. Bervariasinya hasil bahan volatil hasil ekstrak dengan pelarut $n$-heksan, menunjukkan getah kulit batang $A$. toxicaria memiliki bahan volatil yang kompleks. Hasil ekstrak getah $A$. toxicaria untuk dimanfaatkan sebagai bahan pestisida nabati bahan-bahan volatil menjadi penanda (deteksi) untuk aplikasi lanjutan.

\section{$4 \quad$ Kesimpulan}

A. toxicaria yang tumbuh di pulau Kalimantan telah dikenal sebagai tanaman yang kulit batangnya menghasilkan getah. Hasil analisis GC-MS pada pelarut n-heksan menunjukkan adanya senyawa volatil seperti isoforon $(35,795 \%)$, sitronelal $(0,52 \%)$, betapatchoulene $(0,186 \%)$, geranyl asetat $(0,377 \%)$, Z-3 - hexadecene $(0,543 \%)$, geranyl butyrate $(0,323 \%)$, asam palmitat $(0,677 \%)$, terpenol $(0,352 \%)$, terpeniol hidrat $(0,246 \%)$ dan citronellyl acetate $(0,233 \%)$. Sedangkan dalam pelarut etil asetat mengandung betapatchoulene (1,799\%), a-hexyl cinnamaldehyde (0,949\%), alpha-octadecene $(6,135 \%)$, alkohol miristat (3,554\%) dan asam heksadekanoat (5,724\%). Bahan-bahan volatil tersebut memiliki khasiat yang sama dengan kapur barus.

\section{Ucapan Terima Kasih}

Penelitian ini dilaksanakan di Fakultas MIPA Universitas Brawijaya mendapat bantuan ekstraksi dan pemadatan gas $\mathrm{N}_{2}$ saudara Agung Sujatmiko mahasiswa S-1 yang sedang menyelasaikan tugas akhir dan diawasi oleh Bapak Edy Priyo Utomo (Alm) selanjutnya Analisis GC-MS/MS di Laboratorium Pusat IImu Hayati yang tetap diawasi oleh 
almarhum. Pada kesempatan ini penulis mengucapkan terima kasih atas bantuan, saran dan diskusinya.

\section{Daftar Pustaka}

Betina, V., Hussain, H., Kouam, S.F., Dongo, E., Pescitellid, G., Salvadorid, P., Kurtane, T., Krohn K., \& Antialactone. (2008). A new y-lactone from Antiaris africana, and its absolute configuration determinated from TDDFT CD calculations. Natural Product Communications. 200:3(2):215-218.

Carter, C.A., Forney, R.W., Gray, E.A., Gehring, A. M., Scneider, T, L., \& Young, D.B. (1997). Toxicarioside A. Anew cardenolide isolated from Antiaris toxicaria latexderived dart poison. Assigment of the $1 \mathrm{H}$ - and 13C-NMR shifts for an antiarigenin agglycon. Tetrahedron, 53(40): 13557-13566. Press, Beijing. p. 16.

Fujimoto, Y., Suzuki, Y., Kainawa, T., Amiya, T., Hoshi, K., \& Fujino, S. (1983). Studies on the Indonesian Antiaris-toxicaria sap. Journal of Pharmacobio-Dynamics, 6(2): 128135.

Gan, Y., Mei, W., Zeng, Y., Han, Z \& Dai, H. (2008). Liposoluble componens and their antioxidant activities from toxicaria latex. Redai Yeredai zhiwu Xoebao, 16(2): 144147.

Jiang, M.M., Gao, H., Dai, Y., Zhang, X., Wang, N. L., \& Yao, X. S. (2009). Phenylpropanoid and lignan derivatives from Antiaris toxicaria and their effect on proliferation and differention of an osteoblast-like. Planta Medica, 75(4): 340-345

Joulain, D., \& König, W. A. (1998). The atlas of spectral data of sesquiterpene hydrocarbons. Hamburg. Verlag: EB-Verlag, Hamburg, Germany.

Kuete V., Vouffo B., Mbaveng A.T., Vouffo E.Y., Siagat R.M., \& Dongo E. (2009). Evaluation of Antiaris africana methanol extracts and compounds for antioxidant and antitumor activities. Pharmaceutical Biology / International Journal of Pharmacognosy, 47 (11): 1042-1049.

Massada Y. (1976). Analysis of essential oils by gas chromatograph and mass spectrometry. New york: Wiley J. \& Sons.

Mei, W.L., Gan, Y.Q.,Dong, M.L., Xiona., \& Hoafu. (2011). Study on the Chemical contituents from Latex of Antiaris toxicaria. Chinese J. of organic chem. 4, 533-537

Nordal, A.. (1963). Meddeleser von Norsk Farmaceutisk Selskap. 25 (10): 155-185 p.

Odugbemi, O. (2008). A textbook of medicinal plants from Nigeria. University of Lagos press.

Okogun, J.I., Spiff, A.I., \& Ekong, D.E.U. (1976). Triterpenoids and betaines from the latex and bark of Antiaris africana. Phytochemistry. 15, 826-827.

Que, D., May, W., Wu, J., Han, Z., \& Dai, H. (2009). Structure elucidation of flavonoids from Antiaris toxicaria roots. Youji Huaxue, 29 (9): 1371-1375.

Shi, L. S., Liao, Y. R., Su, M. J., Lee, A. S., Kuo, P. C., Damu, A. G., \& Wu, T. S. (2010). Cardiac glycosides from Antiaris toxicaria with potent cardiotonic activity. Journal of natural products, 73(7), 1214-1222.

Subiono, T., Abadi, A. L., Himawan, T. (2017). Ligan Activity of Antiaris toxicaria Lesch. and the Role of Toxicarioside in Crude Extract: In Silico, In Vitro, and In Vivo Approaches. IOSR Journal of Biotechnology and Biochemistry. 3(6) 4-10. 